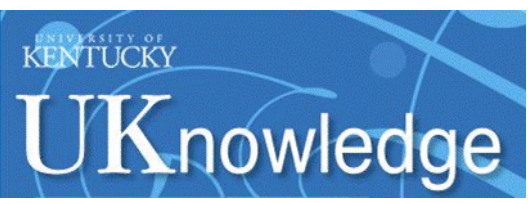

University of Kentucky

UKnowledge

6-2009

\title{
It is More Than Just a Reproductive Healthcare Visit: Experiences from an Adolescent Medicine Clinic
}

\author{
Marlene B. Huff \\ University of Kentucky, mbhuff2@uky.edu \\ Kimberly K. McClanahan \\ University of Kentucky \\ Heather A. Brown \\ University of Kentucky, heatherbrown@uky.edu \\ Hatim A. Omar \\ University of Kentucky, hatim.omar@uky.edu
}

Follow this and additional works at: https://uknowledge.uky.edu/pediatrics_facpub

Part of the Pediatrics Commons

Right click to open a feedback form in a new tab to let us know how this document benefits you.

\section{Repository Citation}

Huff, Marlene B.; McClanahan, Kimberly K.; Brown, Heather A.; and Omar, Hatim A., "It is More Than Just a Reproductive Healthcare Visit: Experiences from an Adolescent Medicine Clinic" (2009). Pediatrics Faculty Publications. 73.

https://uknowledge.uky.edu/pediatrics_facpub/73

This Article is brought to you for free and open access by the Pediatrics at UKnowledge. It has been accepted for inclusion in Pediatrics Faculty Publications by an authorized administrator of UKnowledge. For more information, please contact UKnowledge@lsv.uky.edu. 
It is More Than Just a Reproductive Healthcare Visit: Experiences from an Adolescent Medicine Clinic

\section{Digital Object Identifier (DOI)}

http://dx.doi.org/10.1515/IJAMH.2009.21.2.243

Notes/Citation Information

Published in International Journal of Adolescent Medicine and Health, v. 21, no. 2, p. 243-248.

(c) Freund Publishing House Ltd.

The copyright holder has granted permission for posting the article here. 


\title{
It is more than just a reproductive healthcare visit: Experiences from an adolescent medicine clinic
}

\author{
Marlene B Huff, PhD, Kimberly K McClanahan, PhD, Heather A Brown, BS and \\ Hatim A Omar, MD
}

Division of Adolescent Medicine, Department of Pediatrics, University of Kentucky, Lexington, KY, USA

\begin{abstract}
The gynecologist may be the only physician that an adolescent depends on for primary and reproductive healthcare services. Because adolescent females often make personal healthcare decisions without the benefit of supportive parents/caregivers, it is imperative that the gynecologist understands the developmental issues encountered during this phase of life. The objective of this study is to identify cited complaints of adolescent females seeking reproductive care and, thus, provide gynecologists with needed information about the medical/mental health issues that may be encountered during routine reproductive care exams. The study group was adolescent females between the ages of 12 and 20 years old. The medical records of 479 adolescent females seeking reproductive care from an adolescent medicine clinic at a southeastern teaching medical center were reviewed to determine the most frequently cited medical/mental health complaints of adolescent females initiating a "routine" gynecological exam. Results indicated that adolescent females present for "routine" reproductive care exams with a myriad of concerns without formally requesting medical/mental health intervention upon initial presentation. The identified primary healthcare needs of adolescent females seeking reproductive healthcare include: 1) issues related to reproductive dysfunction (60\%); 2) gastroenterological pain/issues (15\%) 3) mental health issues (15\%) and 4) general medical physical complaints $(10 \%)$. Gynecologists are often asked to serve as a primary care provider as well as a reproductive healthcare specialist. Identification of the specific healthcare needs (reproductive and otherwise) of adolescent females will assist gynecologists in being uniquely prepared to practice in the setting of their choice.
\end{abstract}

Keywords: Adolescent reproductive care, adolescent medicine, adolescent gynecology

Correspondence: Professor Hatim A Omar, MD, J422 Kentucky Clinic, University of Kentucky, Lexington, KY 40536-0284, United States. Tel: 859-323-5643; fax: 859-323-3795; E-mail: hatim.omar@uky.edu

Submitted: November 01, 2007. Revised: November 20, 2007. Accepted: November 21, 2007.

\section{INTRODUCTION}

An increased awareness of gynecological healthcare among adolescents has resulted in additional females seeking this type of care. Yet, the exact location where adolescent reproductive care is provided within hospitals and clinics is often unclear. General pediatric clinics may be unequipped or staffed inappropriately to effectively address the gynecological needs of adolescents, and many pediatricians lack confidence in their ability to treat adolescents (1). Gynecology, internal medicine, and family practice physicians may find adolescent medicine cutside their area of expertise. Furthermore, adolescent healthcare may be 
considered too time-consuming to be managed in a private practice setting (2-4). Finally, adolescents may find visits with non-pediatric practitioners to be unwelcoming and insufficient (5).

Primary care physicians provide most of the reproductive health care services for adolescents (6). For those not seen in primary care clinics, the gynecologist may be the only physician with whom an adolescent has a relationship and therefore needs both primary and reproductive care. Ideally, parents play an integral role in assisting their daughters to manage their own healthcare. In the case of reproductive issues, there are times when parental involvement is detrimental to care, and confidentiality becomes paramount from the perspective of the adolescent. Parents may be completely unaware of the reproductive health care needs of their daughters. In fact, adolescent patients often avoid seeking appropriate care or break the continuity of care with a physician, particularly for reproductive health needs, unless an assurance of confidentiality is provided (7). Adolescents are also more likely to discuss sexually transmitted diseases, pregnancy prevention, and other sensitive topics when confidentiality is assured proactively by their gynecologist (8). Because young females are often making healthcare decisions without the benefit of supportive parents/caregivers, that the gynecologist understand the range of medical/mental health issues presented during a reproductive exam is imperative.

\section{Adolescent reproductive care}

Encouraging adolescent females to seek and continue to obtain reproductive healthcare is an important issue for gynecologists and primary care physicians alike. Even though great strides have been made in detecting and treating such cancers as cervical cancer among adolescents, the risk remains. The relative risk for cervical cancer is 0.25 to 0.37 in women screened through Pap smears compared with those who have never been screened (9-10). The rates of abnormal cervical cytology are high among young women in the United States; a Centers for Disease Control and Prevention report found that in women under age 30 , $8.3 \%$ of first-round Pap tests showed ASCUS, 9.4\% LSIL, 2.7\% HSIL, and less than $0.1 \%$ squamous cell cancer (11). Sexually active adolescent girls may be at even higher risk for developing cervical dysplasia because of early coitarche, increased numbers of sexual partners, higher incidence of sexually transmitted the infections, higher rates of smoking, and vulnerability of the adolescent cervix to the acquisition of sexually transmitted disease and initiation of carcinogenesis (12).

In addition to the myriad of sound medical reasons why all female adolescents should have reproductive health care, it may be that impoverished females are especially in need of this type of care. Indeed, certain evidence indicates that preadolescents and adolescents enrolled in Medicaid and seeking reproductive health services have an elevated likelihood of sexual abuse or engagement in criminal behavior, both before and after their reproductive health visits (13). In logistic regression analyses that controlled for age at Medicaid enrollment, length of enrollment, and demographic factors, adolescents with a reproductive health claim were more likely than other Medicaid enrollees to be referred for any reason to child protective services (odds ratio, 2.9) or to have experienced physical (1.6) or sexual abuse (2.3) during the study period (13). The odds of physical abuse were especially elevated among young women who had undergone an abortion (2.3); those who had received 
pregnancy care had particularly high odds of sexual abuse (3.2). One-fourth of referrals for physical or sexual abuse exams were made within the month preceding or following the young women's first claim for reproductive health services; $60 \%$ were made within 6 months before or after the claim (13). These findings may not be generalized to preadolescents or adolescents who are ineligible for Medicaid because poverty may increase a young woman's risk of abuse, criminal activity, and early sexual initiation. Factors such as ethnic makeup and the availability of services in a particular community could also affect outcomes for young women.

\section{Adolescent mental health care}

Studies have shown that greater than $20 \%$ of adolescents in the general population have emotional problems, and one-third of adolescents attending psychiatric clinics suffer from depression (14-16). Moreover, the suicide rate for adolescents has increased more than $200 \%$ over the last decade (17). Adolescent suicide is now responsible for more deaths in youths aged 15 to 19 years than is cardiovascular disease or cancer. Despite this predominance, mood disorders among adolescents are greatly underdiagnosed, leading to serious difficulties in school, in work, and in personal adjustment, which may continue into adulthood.

Anxiety disorders are among the most common mental, emotional, and behavioral problems to occur during childhood and adolescence. About 13 of every 100 children and adolescents from age 9 to 17 experience some kind of anxiety disorder; girls are affected more than boys (18). About half of children and adolescents with anxiety disorders have a second disorder or other mental or behavioral disorder, such as depression. In addition, anxiety disorders can coexist with physical health conditions requiring treatment (18).

\section{METHODS}

After receiving approval from the university research institutional review board, the researchers reviewed the charts of 479 adolescent females, who received reproductive care at an adolescent medicine clinic located in a southeastern teaching medical center to determine the specific medical/mental health complaints presented at the time of a routine gynecological exam. The adolescent patients requested a "routine gynecological exam", when making the original appointment without identifying other medical or mental health issues. A routine gynecological exam may include pelvic exams and/or pap smears depending upon the needs of the patient.

Two data analysis programs were used to analyze the data. nVivo (Version 7), a qualitative data analysis program, was used to analyze the content of the medical notes written by the attending physician and resident(s) assigned to the adolescent medicine clinic. No significant differences in the content of the resident notes versus those of the attending physician were found. Demographic data, including the respondents' age, dates of initial reproductive exam, as well as any follow-up reproductive exams were noted. An examination of residents and attending physician medical notes provided detailed explanations of the complaints that arose during the examination. The Statistical Package for the Social Sciences (Version 15) was used to analyze quantitative data and the results are presented below.

\section{RESULTS}

Four hundred seventy-nine retrospective medical chart reviews were completed. The age range of the patients examined was 12 20 years of age with the majority (80\%) 
Table 1. Age distribution of female adolescents seeking routine reproductive health care

\begin{tabular}{cc}
\hline \multicolumn{1}{c}{ Age } & Total (\%) \\
\hline $12-14$ years & $38(8)$ \\
$14.1-16$ years & $129(27)$ \\
$16.1-18$ years & $254(53)$ \\
$18.1-20$ years & $58(12)$ \\
\hline Total & $479(100)$ \\
\hline
\end{tabular}

Table 2. Distribution of primary medical/ mental health complaints reported by' the participants $(N=479)$

\begin{tabular}{lc}
\hline Mledical/Mental Ilealth Complaint & Total (\%) \\
\hline Reproductive Dysfunction & $287(60)$ \\
Gastroenterological Pain/lssues' & $72(15)$ \\
Mental Health Issues' & $72(15)$ \\
General medical complaints & $48(10)$ \\
\hline Total & $479(100)$ \\
\hline e.g.. constipation, diarrhea, nausea, vomiting
\end{tabular}

between 14 and 18 years of age. The age distribution is presented in table 1 .

The categories of complaints included the following:

- Medical concerns related to a gynecological condition-pregnancy, sexually transmitted infections, rash(es), abnormal pap smears, cervical dysplasia, amenorrhea, dy'smenorrhea

- Medical concerns unrelated to a gynecological condition-diabetes, hypertension, allergies, asthma, acne, sports injuries

The younger the age of the patient, the more likely that the exam was categorized as "initial, although $3 \%(n=14)$ of the sample had a prior history of sexual abuse and required consistent follow-up for the resulting gynecological issues. Such patients were eliminated from the study as their gynecological exams could not be considered routine.

- Mental health concerns unrelated to any medical condition-Mood disorders. anxiety, body image issues, self-esteem issues

- Mental health concerns related to an associated medical condition-depression secondary to chronic illness, body image issues, self-esteem issues related to obesity, Hyperandrogenism Insulin Resistance Acanthosis Nigricans (HAIRAN) syndrome

Table 2 shows that the majority of female adolescents reported some type of reproductive dysfunction $(60 \%)$ as their primary complaint, whereas $10 \%$ of the participants, even though the original appointment requested was a 'routine' gynecological exam, had general medical complaints that were not associated with specific gynecological issues. Of the sample, $15 \%$ reported primarily experiencing untreated/undertreated mental health issues and requested medical intervention. Many of the same patients reported gastrointestinal pain or related issues (i.e., constipation, diarrhea, nausea and/or vomiting). See table 2 for additional details.

In reviewing the 479 medical charts, 1,496 complaints were noted, as categorized earlier. The majority (83.1\%) of adolescents complained of two to five medical/mental health needs that required physician attention, whereas 71 females (15\%) reported more than five unmet medical'mental health needs. Only nine $(.019 \%)$ participants voiced "no medical/ mental health complaints". See table 3 for a summary of the data. 
Table 3. Distribution of all medical/mental health reported complaints $(N=479)$

\begin{tabular}{lc}
\hline Medical/Mental Health Complaint & Total (\%) \\
\hline Reproductive Dysfunction & $988(66)$ \\
Gastroenterological Pain/lssues ${ }^{1}$ & $182(12$ \\
Mental Health Issues' & $247(16)$ \\
General medical complaints & $79(6)$ \\
\hline Total & $1496(100)$ \\
\hline e.g., constipation, diarrhea, nausea, vomiting
\end{tabular}

\section{DISCUSSION}

Primary health care, as well as reproductive care, are essential components of a comprehensive medical program for adolescents. Physicians of varied specialties provide primary care, but the gynecologist is often the one that the female adolescent primarily depends on for all types of medical care. Therefore, it is essential that gynecologists consider themselves primary care providers as well as reproductive care specialists in certain circumstances. The analogy of the gynecologist as primary care provider is consistent with the study by Horton et al in 1993 (15), which found that more than half of American College of Gynecologists (ACOG) Fellows provided primary and preventive care during more than half of their practice time.

Clearly, gynecologists continue to be the experts on adolescent reproductive health because the majority $(60 \%)$ of the participants requested reproductive care. The participants also cited, however, a variety of medical/mental health issues that were not addressed in other healthcare settings. The reasons for numerous unmet medical/mental health needs are complex and varied. Preadolescents and adolescents that are under-insured or uninsured and encounter barriers to receiving appropriate healthcare may certainly be included in this group of under-served young patients. In addition, the lack of adolescent medicine specialists, as well as an increase in risktaking behaviors that result in higher levels of patient acuity, may lead to lower levels of primary care provision. All these health related issues deserve additional systematic analysis as they relate to adolescent reproductive care.

The results of this study indicate that adolescent females often assume that in addition to reproductive health care, their gynecologist will be able and willing to address a variety of other medical and mental health issues. Although not all gynecologists express a desire to practice primary care, that gynecologists carefully evaluate the type and scope of the practice in which they plan to work is imperative.

\section{REFERENCES}

1. Fisher M, Golden NH, Bergeson R, Bernstein A, Saunders D, Schneider $M$, et al. Update on adolescent health care in pediatric practice. $\mathrm{J}$ Adolesc Health 1996;19(6):394-400.

2. Griffith JR, Schwab KA, Robinson A Hemming VG. Physicians' perceptions of the status of adolescent health care within the military health system. Milit Med 1999;164: 683-7.

3. Akinhami LJ, Gandhi H, Cheng TL. Availability of adolescent health services and confidentiality in primary care services. Pediatrics 2003;111:394-401.

4. Kelts EA, Allan MJ, Klein JD. Where are we on teen sex? Delivery of reproductive health services to adolescents by family physicians. Fam Med 2001; 33:376-81.

5. English A. Reproductive health services for adolescents: Critical legal issues. Obstet Gynecol Clin North Am 2000; 27:195-211. 
6. Udry JR, Bearman PS. The national longitudinal study of adolescent health (AddHealth). University of North Carolina at Chapel Hill: UNC Carolina Population Center. Available at: http:// www.cpc.unc.edu/projects/ addhealth. Accessed 23 June 2007.

7. Klein JD, Wilson KM, McNulty $\mathrm{M}$, Kapphahn C, Collins KS. Access to medical care for adolescents: results from the 1997 Commonwealth Fund Survey of the Health of Adolescent Girls. J Adolesc Health 1999;25(2): 120-30. Erratum in: J Adolesc Health 1999;25(5):312.

8. Thrall JS, McCloskey L, Ettner SL, Rothman E, Tighe JE, Emans SJ. Confidentiality and adolescents' use of providers for health information and for pelvic examinations. Arch Pediatr Adolesc Med 2000;154(9): 885-92.

9. No authors listed. Screening for squamous cervical cancer: duration of low risk after negative results of cervical cytology and its implication for screening policies. IARC Working Group on evaluation of cervical cancer screening programmes. BMJ 1986;293: 659-64.

10. Van der Graaf Y, Vooijs GP, Zeilhuis GA. Cervical screening revisited. Acta Cytol 1990;34:366-72.

11. Centers for Disease Control and Prevention. Results from the national breast and cervical cancer early detection program, October 1, 1991September 30, 1993. MMWR Morb Mortal Wkly Rep 1994;43(29): 530-4

12. Shew ML, Fortenberry JD, Miles P, Amortegui AJ. Interval between menarche and first sexual intercourse, related to risk of human papillomavirus infection. $\mathrm{J}$ Pediatr 1994;125:661-6.

13. Gessner BD. Reproductive health, criminal activity, and abuse among 10 to 15 -year-old females enrolled in Medicaid. Obstet Gynecol 2006;108 (1):111-8.

14. Lewinsohn PM, Clarke GN, Seeley JR, Rohde P. Major depression in community adolescents: age at onset, episode duration, and time to recurrence. J Am Acad Child Adolesc Psychiatry 1994;33(6):809-18.

15. Offer D, Schonert-Reichl KA. Debunking the myths of adolescence: Findings from recent research. J Am Acad Child Adolesc Psychiatry 1992; 31:1003.

16. Fleming JE, Boyle $M$, Offord DR. The outcome of adolescent depression in the Ontario child health study follow-up. J Am Acad Child Adolesc Psychiatry 1993;32:28.

17. Hodgma $\mathrm{CH}, \mathrm{Mc}$ Anarny ER: Adolescent depression and suicide: Rising problems. Hosp Pract 1992;127:73.

18. US Department of Health and Human Services. Mental Health: A Report of the Surgeon General. Rockville, MD: USDHHS, Substance Abuse and Mental Health Services Administration, Center for Mental Health Services, National Institutes of Health, National Institute of Mental Health, 1999.

19. Horton JA, Cruess DF, Pearse WH. Primary and preventive care services provided by obstetrician-gynecologist. Obstet Gynecol 1993;82:723. 